\title{
The Effect of Arch Height and Material Hardness of Personalized Insole on Correction and Tissues of Flatfoot
}

\author{
Shonglun Su, ${ }^{1,2}$ Zhongjun Mo, ${ }^{1,2}$ Junchao Guo, ${ }^{1,2}$ and Yubo Fan ${ }^{1,2}$ \\ ${ }^{1}$ Key Laboratory for Biomechanics and Mechanobiology of Ministry of Education, School of Biological Science and Medical \\ Engineering, Beihang University, Beijing 100086, China \\ ${ }^{2}$ Beijing Key Laboratory of Rehabilitation Technical Aids for Old-Age Disability, Key Laboratory of Rehabilitation Technical Aids \\ Analysis and Identification of the Ministry of Civil Affairs, National Research Centre for Rehabilitation Technical Aids, Beijing \\ 100176, China
}

Correspondence should be addressed to Yubo Fan; yubofan@buaa.edu.cn

Received 5 March 2017; Revised 31 March 2017; Accepted 9 April 2017; Published 12 June 2017

Academic Editor: Rui Zhu

Copyright (C) 2017 Shonglun Su et al. This is an open access article distributed under the Creative Commons Attribution License, which permits unrestricted use, distribution, and reproduction in any medium, provided the original work is properly cited.

\begin{abstract}
Flat foot is one of the common deformities in the youth population, seriously affecting the weight supporting and daily exercising. However, there is lacking of quantitative data relative to material selection and shape design of the personalized orthopedic insole. This study was to evaluate the biomechanical effects of material hardness and support height of personalized orthopedic insole on foot tissues, by in vivo experiment and finite element modeling. The correction of arch height increased with material hardness and support height. The peak plantar pressure increased with the material hardness, and these values by wearing insoles of $40^{\circ}$ were apparently higher than the bare feet condition. Harder insole material results in higher stress in the joint and ligament stress than softer material. In the calcaneocuboid joint, the stress increased with the arch height of insoles. The material hardness did not apparently affect the stress in the ankle joints, but the support heights of insole did. In general, insole material and support design are positively affecting the correction of orthopedic insole, but negatively resulting in unreasonable stress on the stress in the joint and ligaments. There should be an integration of improving correction and reducing stress in foot tissues.
\end{abstract}

\section{Introduction}

The foot and ankle is a complex structure with stability and elasticity, consisting of 28 bones, more than 30 joints, and many intertwined ligaments and tendons [1]. It plays an important role in supporting the body weight. Foot deformity is a very common disease, not only causing pain but also seriously affecting people's health and daily activities [2]. Flatfoot is one of the common deformities, which has a high incidence rate in the Chinese youth population. During the growth period, the mild and moderate flattened feet will be corrected with the growth of soft tissue and bones. Severe flatfoot may result in ligament relaxation, muscle weakness, joint distortion, limb pain, ankle injury, ulcer, and other clinical symptoms, which need for conservative correction or surgical intervention $[3,4]$.
Clinically, correction of orthopedic insoles combined with manual reposition is one of the primary conservation therapies for flexible flatfoot of young patient $[3,4]$. Orthopedic insoles have been revealed to be an effective treatment for flatfoot by elevating the arch height and recovering the body weight supporting and force transmission [5]. Due to the difference between individuals (soft tissue material properties, flatness, etc.), customized orthopedic insole needs to be produced. In the customization process, the insole shape design and material selection of the insole seriously depended on the experience of pedorthist, lack of quantitative theoretical support. Previous study showed that the custom-molded insole could reduce stress compared with the flat insole. The thickness, heel's height, and materials of proper insole could minimize the peak plantar stress and achieve uniform stress distribution [6]. The material and 
arch height of insole in the sport shoes have a significant effect on biomechanical characteristics of the foot $[7,8]$. Therefore, it is necessary to research the biomechanical effect of the design parameters of orthopedic insole, including the material and shape of support and the correction effect of foot arch height, and explore the influence on the foot tissues. Quantified assessment of the design parameters is a benefit to the future design of orthopedic insole to improve treatment effect and to reduce the adverse effects on the patient's foot tissues [9-12].

This study was to evaluate the effects of design parameters including material hardness and support arch height of personalized orthopedic insole on the correction of foot arch and plantar pressure distribution by in vivo experiments and to evaluate the biomechanical effects on the foot tissues, including stress distribution on joint cartilage and ligaments using finite element modeling.

\section{Material and Methods}

Based on a specific patient with flatfoot, this study was to evaluate the effect of design parameters including material hardness (Shore $\mathrm{A}, 30^{\circ}, 35^{\circ}$, and $40^{\circ}$ ) and support arch height $(27 \mathrm{~mm}, 30 \mathrm{~mm}$, and $33 \mathrm{~mm})$ of orthopedic insole on the correction effect of foot arch and plantar pressure distribution by in vivo experiment. In the second step, finite element modeling was adopted to evaluate the biomechanical effects on the foot tissues, including stress distribution on joint cartilage and ligaments.

2.1. Subject and Data Processing. A young subject (12 years old, $160 \mathrm{~cm}$ height, and $55 \mathrm{~kg}$ weight) with severe flatfoot participated this study. The participant was explained on the research purpose and signed the consent form. At first, a series of customized insole of the subject were achieved for the in vivo experiment. CT images including the whole foot and portion crus of the subject were obtained at 0.5 $\mathrm{mm}$ interval and $0.6 \mathrm{~mm}$ resolution using a CT scanner (Brilliance iCT, Philips, Netherlands) under a quasi-weightbearing condition with bare feet, used in the geometrical modeling. The quasi-weight-bearing status ( $275 \mathrm{~N}$ per foot) was produced by a customized equipment that consisted of an adjustable frame and a plane pressure measuring system (Pedar, Novel, Germany). The images were also checked to ensure that the flatfoot does not exhibit any radiographic evidence of tissue deformity symptoms. The study plan was approved by the Ethical Committee of the corresponding institute.

2.2. Customized Insole of the Subject. The foot profile of the subject under weight-bearing and non-weight-bearing conditions was obtained as point contours using a $3 \mathrm{D}$ foot scanner (Infoot, I-Ware Laboratory Co. Ltd. JPN). An insole design software (GeBioM, Go_Tec Inc. GER) was used to develop the $3 \mathrm{D}$ geometrical model of customize insoles according to the participant's foot contours. The general thickness of the insole was designed as $7 \mathrm{~mm}$. In clinical practice, the orthopedic insole is produced basing on non-weightbearing condition, in which the arch shape was close to the normal configuration. Since the arch height of the subject is about $23 \mathrm{~mm}$ in the non-weight-bearing condition, the initial total arch height was setting at $30 \mathrm{~mm}$ and $\pm 3 \mathrm{~mm}$ that were chosen for this parametric study and that were $27 \mathrm{~mm}$ (type I), $30 \mathrm{~mm}$ (type II), and $33 \mathrm{~mm}$ (type III) in sequence, as shown in Figure 1. All these settings were guided by a pedorthist and a therapist. Three kinds of materials, with different hardness (Shores $\mathrm{A}, 30^{\circ}, 35^{\circ}$, and $40^{\circ}$ ), were chosen for its high popularity and sustainability for orthopedic insoles.

2.3. In Vivo Measurement. Wireless in-foot pressure measurement system (F-Scan, Novel Inc., US), which consists of 100 capacitive sensors, was used to test the plantar pressure by wearing the nine different orthopedic insoles (3 arch heights, 3 materials), as shown in Figure 1(a). In the meanwhile, the distance between the mark point on the navicular bone and ground was measured to evaluate the correction effect of different insoles, as shown in Figure 1(b), and to be used in the next FE modeling as the boundary loading conditions to explore the effect on the foot tissues.

2.4. Finite Element Modeling of Flatfoot. Medical image processing software (Mimics 10.1, Materialise Inc., Belgium) was used to segment the CT images to acquire the boundaries of each foot bone and skin surface to reconstruct the geometry models. Then, the geometries were imported into a reverse engineering software (Rapidform XOR3, INS Techology Inc., US) to edit the geometry with operations, such as smoothing and partition, and reconstruct the geometry as nurbs format. In total, the model included 28 bony structures, including tibia, fibia, talus, and calcaneus, as shown in Figure 2. The joint regions on the bone were extracted separately and rebuilt into solid blocks by thickening operation with a depth of $0.4 \mathrm{~mm}$ to reconstruct joint cartilages. Seventy-two major ligaments, deep fascia, superficial fascia, and nine major extrinsic muscle groups controlling foot movement were included and defined by connecting the corresponding anatomical attachment sites on the bones.

The FE package, ABAQUS 6.13 (Simulia Inc., US), was used for assembling the foot components, creating of the FE mesh, and implicit solver was employed for the subsequent analysis. The insertion points of the ligaments, the interface of skin, and the interfaces of the joint cartilage were fixed onto the corresponding regions on the bony structure by tie constraint formulation to assemble the foot components. The interaction among interfaces of joint cartilage was assigned with frictionless sliding contact formulation.

The material properties of each component of the foot tissues and insoles were selected from the literature and listed in Table 1 [13-18]. The element type of the foot tissues and insoles obtained by multimeshing techniques is listed in Table 1, together with the material properties. The element sizes for bone and skin were 2.5 and $1.5 \mathrm{~mm}$, respectively, that resulted in a total of 94,522 nodes and 306,289 elements. Convergence within $3 \%$ in joint cartilage stress was achieved in bare feet weight-bearing condition, to ensure that the results were irrelevant to the mesh density $[19,20]$. 


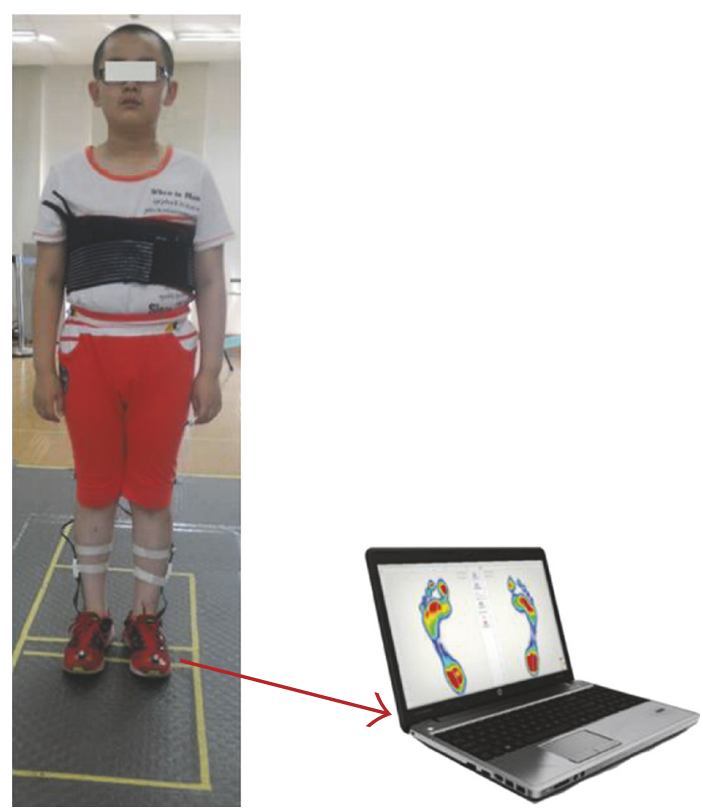

(a)

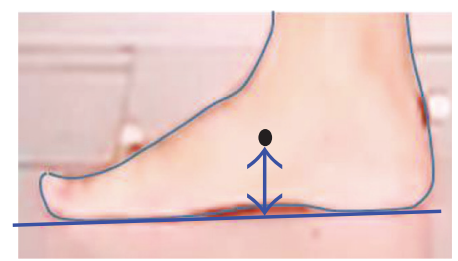

(b)
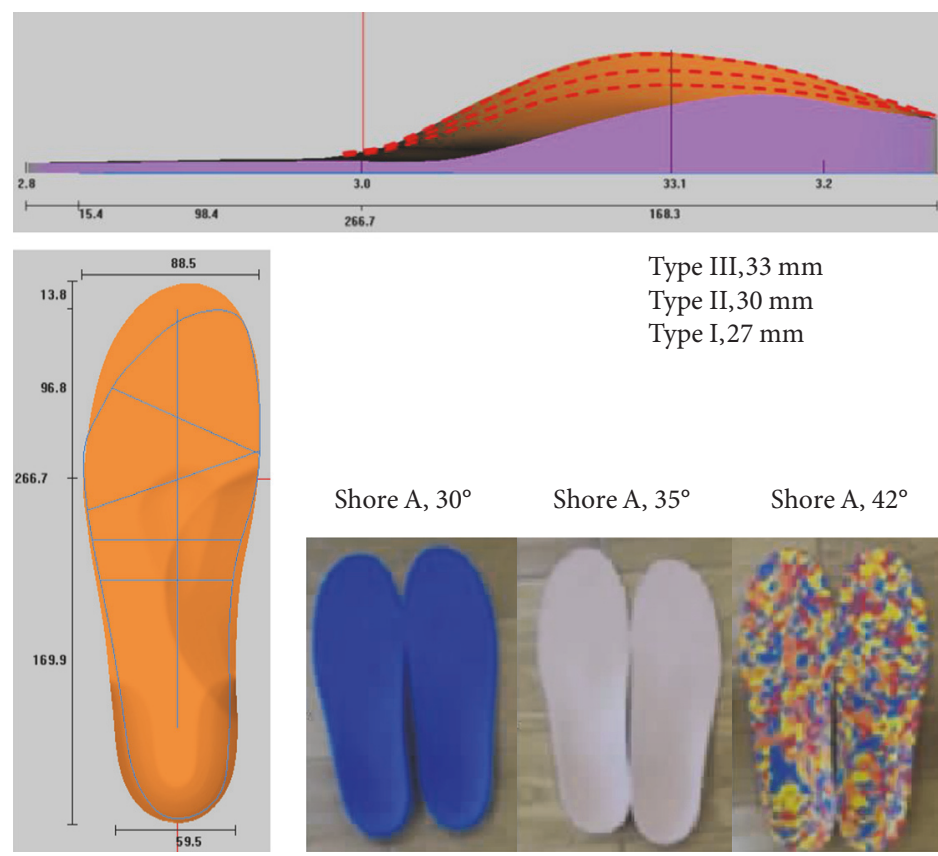

Type III, $33 \mathrm{~mm}$

Type II,30 mm

Type I,27 mm

Shore A, $30^{\circ} \quad$ Shore A, $35^{\circ} \quad$ Shore A, $42^{\circ}$

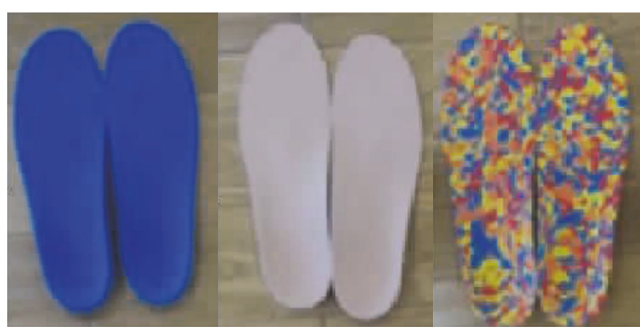

(c)

FIGURE 1: Illustration of in vivo measurement, (a) plantar pressure measurement, (b) displacement measurement of the navicular bone, and (c) insole material hardness and design sketch.

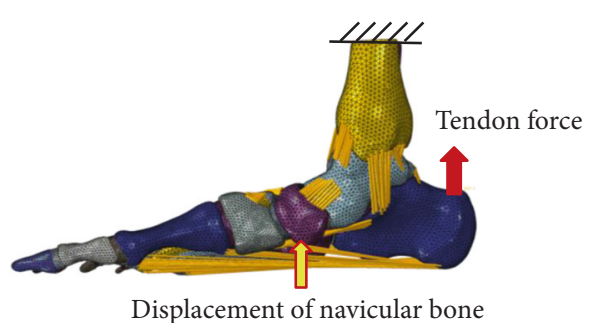

FIGURE 2: Finite element model of flatfoot and its components.
Prior to applying the correct loading on the navicular bone condition, the superior cross section surface of the tibia, fibula, and skin was fixed at the six degrees of freedom, and the initial tendon force of $375 \mathrm{~N}$ was properly adjusted until the foot was properly aligned relative to the insole [15-17]. In the second step, the displacement of the navicular bone achieved in the previously described in vivo experiment was applied on the reference point of the navicular bone in vertical direction by keeping the freedom in other direction to 
TABle 1: Material mechanical properties and element types of the FE model.

\begin{tabular}{lcccc}
\hline Component & Element type & Young's modulus E (MPa) & Poisson's ratio & ${\text { Cross-sectional area }\left(\mathrm{mm}^{2}\right)}^{2}$ \\
\hline Bony structures & 3D tetrahedra & 7300 & 0.3 & - \\
Soft tissue & 3D tetrahedra & 1.19 & 0.48 & - \\
Plantar fascia & 3D tetrahedra & 350 & 0.35 & - \\
Cartilage & 3D tetrahedra & 10 & 0.4 & $18.4 \sim 260$ \\
Ligaments & Tension-only truss & $0 \sim 700$ & 0.4 & - \\
Skin & 3D tetrahedra & 1 & 0.3 & - \\
Plantar support & 3D hexahedron & 21,0000 & \\
\hline
\end{tabular}

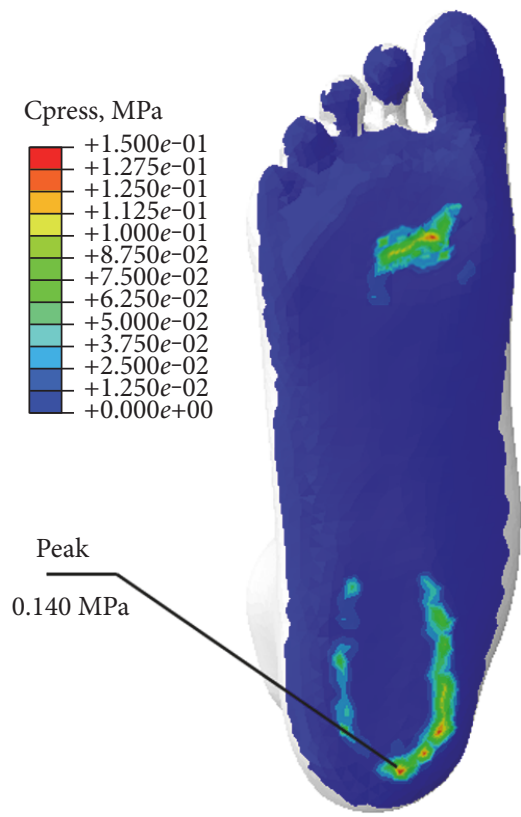

(a)

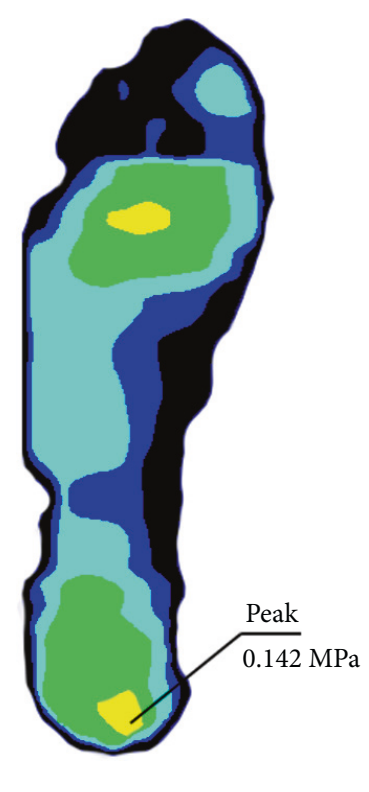

(b)

FIGURE 3: Plantar pressure distribution in (a) FE model and (b) F-Scan measurement.

allow coupling motion and to simulate the correcting effect of different orthopedic insoles.

2.5. Finite Element Model Validation. Validation is one of the important stages in finite element modeling. This flatfoot model was validated by comparing the plantar pressure in FE model and in vivo measurement, under weight-bearing with bare foot on a flat plane.

\section{Results}

Nine customize insoles ( 3 arch heights, 3 hardness materials) were manufactured. The height between the navicular bone and the ground and the plantar pressure by wearing the different customize insoles were achieved in the in vivo experiment. By the finite element modeling, the stress in the joint cartilage and ligaments was extracted.

3.1. Validation of Flatfoot Model. As shown in Figure 3, the plantar pressure distribution in FE model was similar with F-Scan data and the peak plantar pressure was $140.0 \mathrm{KPa}$ and $142 \mathrm{KPa}$ in FE model and F-Scan measurement, respectively. It meant that the FE flatfoot could provide reasonable results in the present research purpose.

3.2. Correction in Foot Arch Height. In bare foot and weightbearing condition, the distance between the navicular bone and the foot bottom (arch height) was about $16.6 \mathrm{~mm}$. The displacement of the navicular bone in the vertical direction by wearing orthopedic insoles is shown in Figure 4 . The foot arch height increased with the material hardness and arch shape of the insole. By wearing insoles made up by material with hardness of $30^{\circ}$, the arch height increased by $43 \%$, $66 \%$, and $83 \%$ with insoles of types I, II, and III, respectively. By wearing the insoles with material hardness of $35^{\circ}$, the arch height increased by $65 \%, 90 \%$, and $103 \%$ with insoles of types I, II, and III, respectively. By wearing insoles with material hardness of $40^{\circ}$, the arch height increased by $80 \%, 97 \%$, and $110 \%$ with insole of types I, II, and III, respectively.

3.3. Plantar Pressure Distribution. Plantar pressure is one of the most important parameters reflecting the interaction 


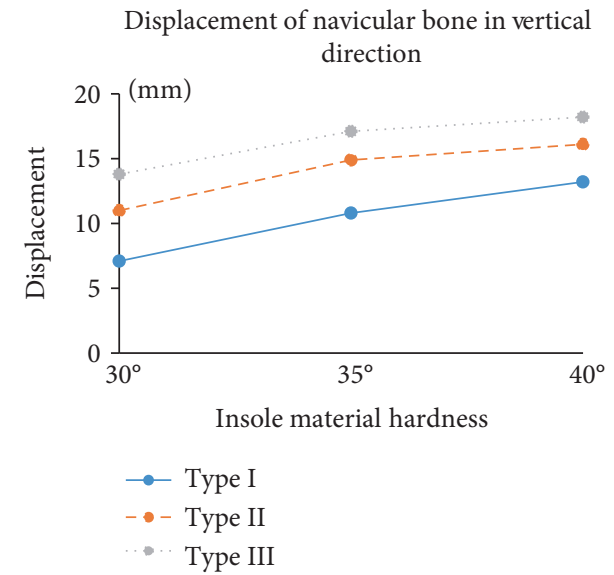

FIgURE 4: Displacement of the navicular bone in the vertical direction.

between the foot and insole. The peak plantar pressure and its distribution in the in vivo experiment are shown in Figure 5. In bare feet condition, the maximal plantar pressure was about $142 \mathrm{KPa}$. Regardless the insole shape, the peak plantar pressure increased with the material hardness. Regardless the material hardness, the maximal plantar pressure was not apparently increased by wearing types I and II insoles. However, the pressure was apparently increased by wearing type III insoles. By wearing insoles made up by the material hardness of $40^{\circ}$, regardless the shapes (types I, II, and III), the plantar pressure was higher than the bare feet condition.

3.4. Stress in the Primary Foot Joints. The maximal stress in the cartilage of the primary foot joints (talonavicular, calcaneocuboid, tibiotalar, and talofibular joints) is shown in Figure 6. In the joint of the middle foot (talonavicular joint and calcaneocuboid joint), the maximal stress increased with the material hardness. In the calcaneocuboid joint, the stress increased with the arch height of insoles. However, in the talonavicular joint, type II insole results in the greatest cartilage stress. The stress in the middle joint was relatively much lower than the ankle joints (tibiotalar joint and talofibular joint). The material hardness did not apparently affect the stress in the ankle joints, but the arch height of orthopedic insoles did.

3.5. Stress in the Primary Foot Ligaments. The maximal stress in the primary foot ligaments is shown in Figure 7. Unlike in the joint cartilage, the maximal stress in almost all the primary foot ligaments increased with the material hardness and arch height of the orthopedic insoles.

\section{Discussion}

Correction and protection of orthopedic insole is a widely used physical therapy for the treatment of adolescent flat feet $[16,21,22]$. However, the corrective effectivity is significantly related with the insole shapes and material hardness. An optimal design of personalized orthopedic insole could greatly improve the foot supporting function and prevent the occurrence of symptomatic complications. Previous study showed that the custom-molded insole reduced maximum stress $40 \%$ more than the flat surface insole. In the increase of insole thickness, stress distribution becomes more uniform and maximum stress value decreases up to $10 \%$ [6].

It was reported that orthopedic insole could improve the patient's foot arch, hereby relieving foot pain, preventing inflammation of soft tissue and tendon sheath and other pathological features [7]. However, there is little knowledge about the changes in the internal skeleton and of medial longitudinal arch by wearing orthopedic insole. In this study, the influence of design parameters, including material hardness and support arch height of personalized orthopedic insole on the correction of foot arch and plantar pressure distribution, and the biomechanical effects on the foot tissues, including stress distribution on joint cartilage and ligaments, were quantitatively analyzed by in vivo experiment and finite element modeling. The results showed that the foot arch height increased with the material hardness and arch shape of the insole. The insole with harder material and higher scaffold of the medial longitudinal arch elevate higher foot arch [23-25]. By wearing the insole made up with the material of $40^{\circ}$ and type III shape, the arch height was elevated up to twice of the initial bare foot weight-bearing condition.

Plantar pressure is one of the most important parameters reflecting the interaction between the foot and insole $[5,25,26]$. It was found that the hardness of the insole material will affect the plantar pressure distribution and the peak value, and affect the trajectory of plantar pressure center, and hereby affect trajectory of upper body gravity center [22]. Regardless the insole shape (types I, II, and III), the peak plantar pressure increased with the material hardness that means harder material results in higher plantar pressure. The peak plantar pressure was not apparently increased by wearing types I and II insoles, but apparently increased by wearing type III insoles. By wearing insoles made up by material with hardness of $40^{\circ}$, regardless the shapes (types I, II, and III), the plantar pressure was higher than the bare feet condition in which it was about $142 \mathrm{KPa}$.

Cartilage injury and joint dislocation are the primary reasons for foot pain in many patients [25]. Orthopedic insole is used to correct the foot arch height and relieve the pain. The purpose of correcting foot arch height is to redistribute the force transfer pattern in the joints to avoid further damaging of foot tissues. However, in the clinical practice, wearing orthopedic insoles is more painful than nonwearing condition in short-term follow-ups. It means that there is an effect on the foot tissues like the ligament and joints by wearing orthopedic insole, at last in short-term follow-ups. In the primary middle joints (talonavicular joint and calcaneocuboid joint), the maximal stress increased with the material hardness. In the calcaneocuboid joint, the stress increased with the arch height of insoles, meaning higher insole arch height results in greater joint stress. However, in the talonavicular joint, type II insole results in the greatest cartilage stress. Despite that, the stress in the middle joint was relatively much lower than that in the ankle joints (tibiotalar joint and talofibular joint), which are the primary structure transferring body weight to the foot. The material hardness did not apparently 


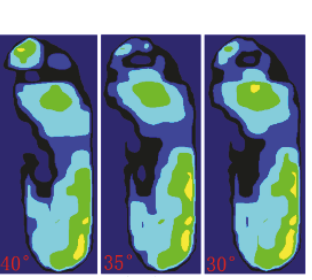

Type I

Plantar pressure distribution

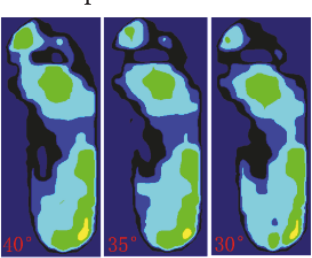

Type II

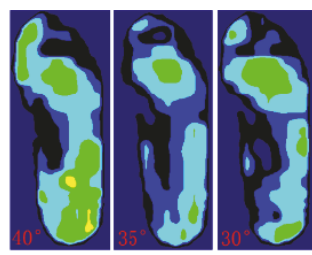

Type III

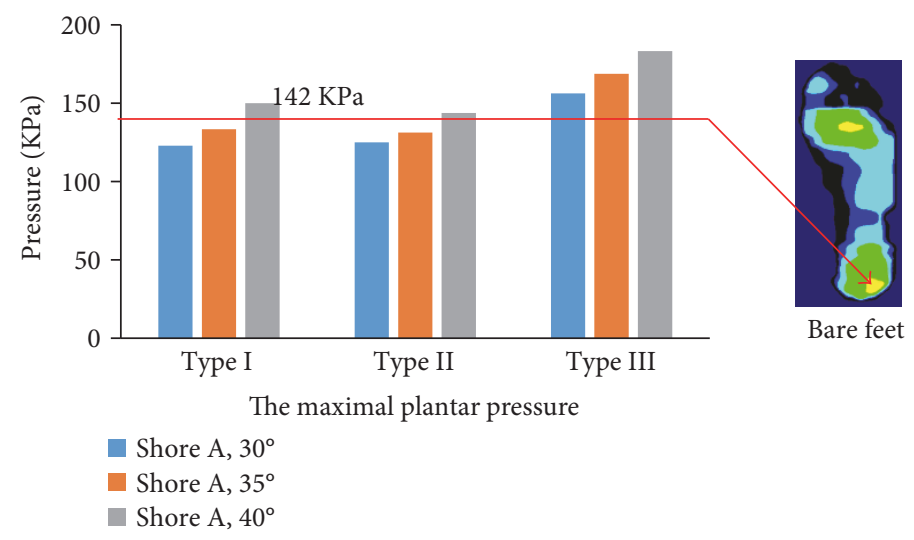

FIGURE 5: The maximal plantar pressures and pressure distribution in the in vivo measurement.
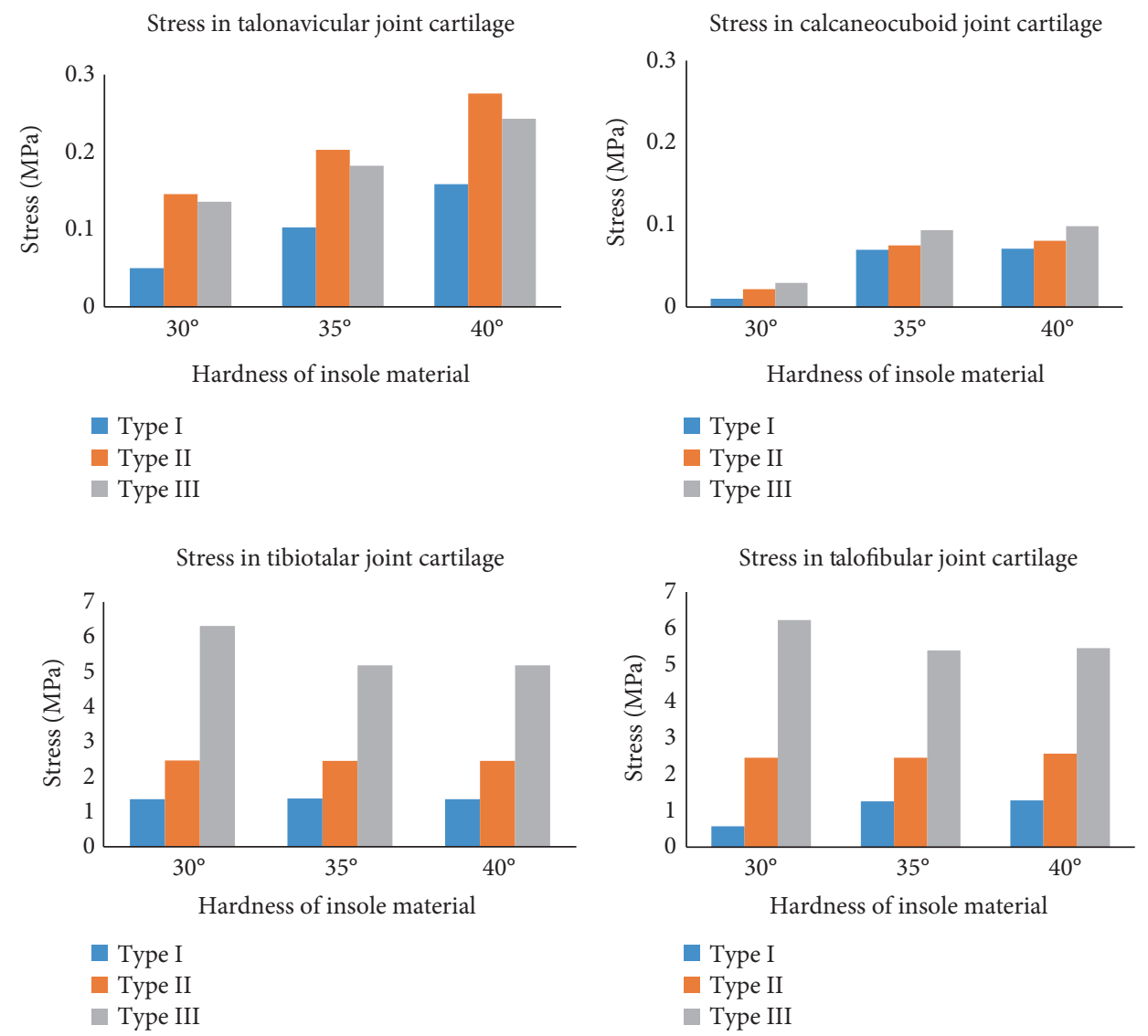

Type I

Type II

Type III

FIgURE 6: The maximal stress in joint cartilage in the finite element model. 

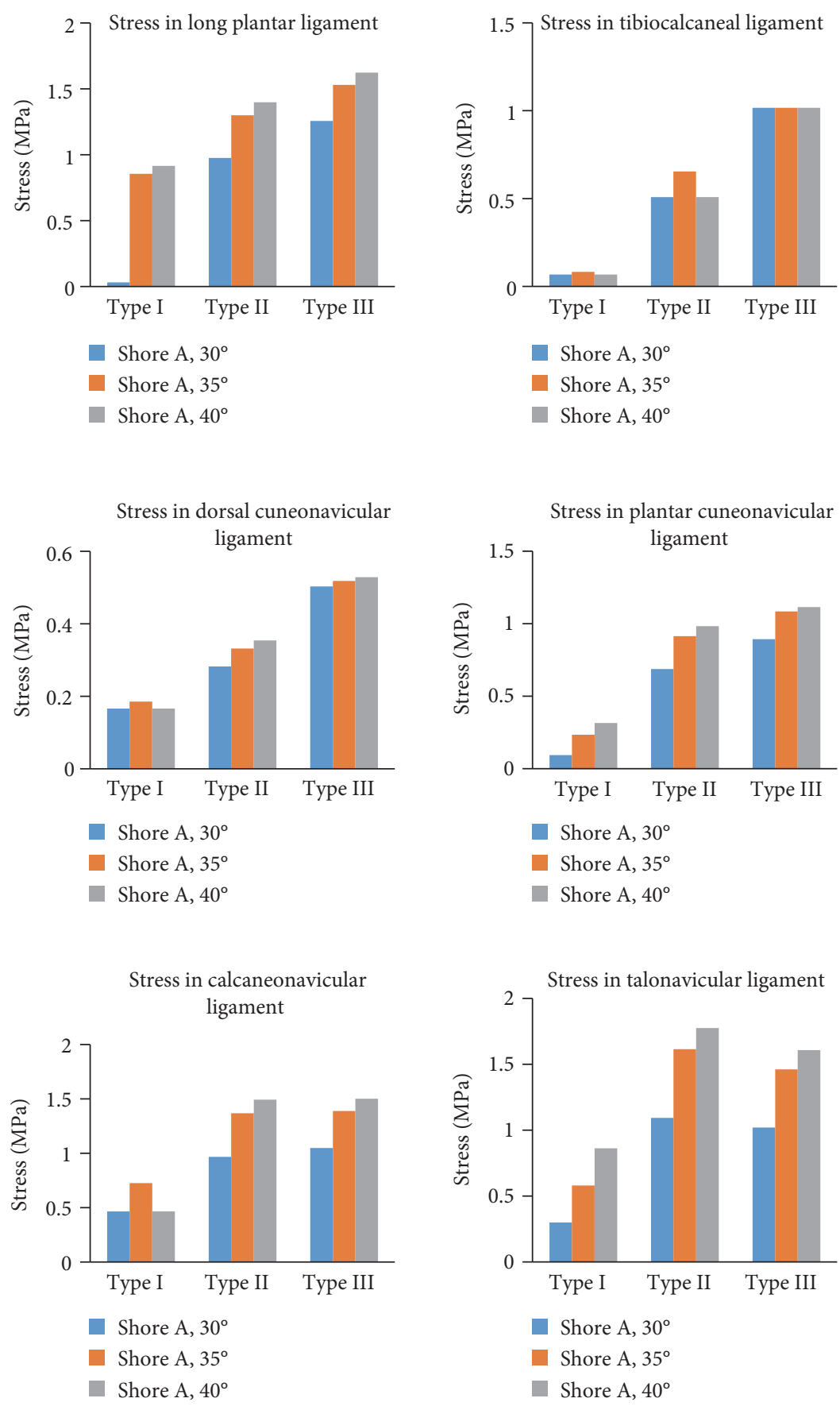

Figure 7: The maximal stress in the foot ligaments in the finite element model.

affect the stress in the ankle joints, but the arch height of orthopedic insoles did. However, the maximal stress in almost all the primary foot ligaments increased with the material hardness and arch height of the orthopedic insoles.

In a previous study, the authors found that by changing the material of the insole, the value of maximum stress remains nearly constant [6]. In this study, material hardness of $30^{\circ}, 35^{\circ}$, and $40^{\circ}$ and arch height of $27 \mathrm{~mm}, 30 \mathrm{~mm}$, and $33 \mathrm{~mm}$ were chosen for analysis. The biomechanical effects on the flatfoot of the arch height (increase with $3 \mathrm{~mm}$ interval) were more sensitive than the material hardness (increase with 5 intervals). For example, the average plantar pressure with type I, type II, and type III insoles was 10.4, 14.0, and 16.4 MPa (standard deviation: $\mathrm{SD}=3.0 \mathrm{MPa}$ ), respectively, while the average plantar pressure with material hardness of $30^{\circ}, 35^{\circ}$, and $40^{\circ}$ was $10.6,14.3$, and $15.8 \mathrm{MPa}$ $(\mathrm{SD}=2.7 \mathrm{MPa})$. The average stress in dorsal cuneonavicular ligament was $0.17 \mathrm{MPa}, 0.32 \mathrm{MPa}$, and $0.52 \mathrm{MPa}(\mathrm{SD}=$ $0.17 \mathrm{MPa}$ ) for insole shape, but $0.32 \mathrm{MPa}, 0.35 \mathrm{MPa}$, and $0.35 \mathrm{MPa}(\mathrm{SD}=0.018 \mathrm{MPa})$ for material hardness.

Several limitations of this study should be noted for the interpretations and applications of the predicted results. 
The correction stage of flatfoot might influence the biomechanical evaluation eventually. However, the biomechanics was just evaluated for the first stage of orthopedic insole treatment. Evaluation of long-term effect should be done in the future. Since there were differences between individuals (degree of flatness, flexible of foot arch, material property, etc.), it is limited to apply the findings obtained from only one subject to all flatfoot. Fortunately, it was a selfcomparison and parametric study, especially the FE foot model could represent patients with similar tissue geometry and arch height. Muscle forces play important role by keeping foot stability and providing stiffness. However, only tendon force was considered in the present study. The displacement of navicular bone based on the in vivo experiment was used as a displacement loading to simulate to corrective function of orthopedic insole, which might not reflect the interaction of insole and skin. In addition, the material property of the foot tissues which was simplified as linear formulation and achieved for the literature weakens the individual characters. However, as a parameterized study of material hardness and shape of insole, this simplification should induce a universal support of orthopedic insole design.

\section{Conclusion}

In general, insole material and support design are positively affecting the correction of orthopedic insole, but negatively resulting in unreasonable stress on the stress in the joint and ligaments. There should be an integration of improving correction and reducing stress in foot tissues.

\section{Conflicts of Interest}

There is no conflict of interest disclosure to be declared by the authors.

\section{Authors' Contributions}

Honglun $\mathrm{Su}$ and Zhongjun Mo contributed equally to this work.

\section{Acknowledgments}

This project was supported by the National Natural Science Foundation of China (nos. 11572029, 11421202, and 11602063), the National Key Research and Development Program in China (2016YFB1101101, 2016YFB1101105), and the 111 Project (no. B13003).

\section{References}

[1] A. Kelikian and S. Sarrafian, Sarrafian's Anatomy of the Foot and Ankle: Descriptive, Topographic, Functional, Lippincott Williams \& Wilkins, Philadelphia, PA, USA, 2011.

[2] A. A. Buerk and M. C. Albert, "Advances in pediatric foot and ankle treatment," Current Opinion in Orthopaedics, vol. 12, no. 6, pp. 437-442, 2001.

[3] G. S. Murley, H. B. Menz, and K. B. Landorf, "A protocol for classifying normal- and flat-arched foot posture for research studies using clinical and radiographic measurements," Journal of Foot and Ankle Research, vol. 2, no. 1, p. 22, 2009.

[4] F. Hefti and R. Brunner, "Flexible arch of the foot," Der Orthopäde, vol. 28, no. 2, pp. 159-172, 1999.

[5] J. S. Lee, K. B. Kim, J. O. Jeong, N. Y. Kwon, and S. M. Jeong, "Correlation of foot posture index with plantar pressure and radiographic measurements in pediatric flatfoot," Annals of Rehabilitation Medicine, vol. 39, no. 1, pp. 10-17, 2015.

[6] A. Sarikhani, A. Motalebizadeh, S. Asiaei, and B. Kamali Doost Azad, "Studying maximum plantar stress per insole design using foot CT-Scan images of hyperelastic soft tissues," Applied Bionics and Biomechanics, vol. 2016, Article ID 8985690, 6 pages, 2016.

[7] D. R. Bonanno, K. B. Landorf, and H. B. Menz, "Pressurerelieving properties of various shoe inserts in older people with plantar heel pain," Gait \& Posture, vol. 33, no. 3, pp. 385-389, 2011.

[8] Y. Han, D. Duan, K. Zhao, X. Wang, L. Ouyang, and G. Liu, "Investigation of the relationship between flatfoot and patellar subluxation in adolescents," The Journal of Foot and Ankle Surgery, vol. 56, no. 1, pp. 15-18, 2017.

[9] S. E. Van Aman and L. C. Schon, "Subtalar Arthroereisis as adjunct treatment for type II posterior tibial tendon deficiency," Techniques in Foot \& Ankle Surgery, vol. 5, no. 2, pp. 117-125, 2006.

[10] Y. H. Kwak, K. B. Park, H. W. Park, and H. W. Kim, "Use of allograft in skeletally immature patients for calcaneal neck lengthening osteotomy," Yonsei Medical Journal, vol. 49, no. 1, pp. 79-83, 2008.

[11] G. V. Viegas, "Reconstruction of the pediatric flexible planovalgus foot by using an Evans calcaneal osteotomy and augmentative medial split tibialis anterior tendon transfer," The Journal of Foot and Ankle Surgery, vol. 42, no. 4, pp. 199-207, 2003.

[12] V. S. Mosca, "Calcaneal lengthening for valgus deformity of the hindfoot. Results in children who had severe, symptomatic flatfoot and skewfoot," The Journal of Bone \& Joint Surgery, vol. 77, no. 4, pp. 500-512, 1995.

[13] J. Guo, L. Wang, W. Chen, C. Du, Z. Mo, and Y. Fan, "Parametric study of orthopedic insole of valgus foot on partial foot amputation," Computer Methods in Biomechanics and Biomedical Engineering, vol. 19, no. 8, pp. 894-900, 2016.

[14] J. Guo, L. Wang, Z. Mo, W. Chen, and Y. Fan, "Biomechanical analysis of suture locations of the distal plantar fascia in partial foot," International Orthopaedics, vol. 39, no. 12, pp. 23732380, 2015.

[15] J. Guo, L. Wang, Z. Mo, W. Chen, and Y. Fan, "Biomechanical behavior of valgus foot in children with cerebral palsy: a comparative study," Journal of Biomechanics, vol. 48, no. 12, pp. 3170-3177, 2015.

[16] J. Yu, J. T. Cheung, D. W. Wong, Y. Cong, and M. Zhang, "Biomechanical simulation of high-heeled shoe donning and walking," Journal of Biomechanics, vol. 46, no. 12, pp. 2067-2074, 2013.

[17] J. Yu, J. T. Cheung, Y. Fan, Y. Zhang, A. K. Leung, and M. Zhang, "Development of a finite element model of female foot for high-heeled shoe design," Clinical Biomechanics, vol. 23, Supplement 1, pp. S31-S38, 2008.

[18] J. T. Cheung and M. Zhang, "Parametric design of pressurerelieving foot orthosis using statistics-based finite element 
method," Medical Engineering and Physics Medical Engineering and Physics, vol. 30, no. 3, pp. 269-277, 2008.

[19] Z. Mo, Q. Li, Z. Jia, J. Yang, D. W. Wong, and Y. Fan, "Biomechanical consideration of prosthesis selection in hybrid surgery for bi-level cervical disc degenerative diseases," European Spine Journal, vol. 26, no. 4, pp. 1181-1190, 2017.

[20] Z. Mo, Y. Zhao, C. Du, Y. Sun, M. Zhang, and Y. Fan, "Does location of rotation center in artificial disc affect cervical biomechanics?” Spine, vol. 40, no. 8, pp. E469-E475, 2015.

[21] E. Kim and J. S. Kim, "The effects of short foot exercises and arch support insoles on improvement in the medial longitudinal arch and dynamic balance of flexible flatfoot patients," Journal of Physical Therapy Science, vol. 28, no. 11, pp. 31363139, 2016.

[22] B. Y. Tsung, M. Zhang, A. F. Mak, and M. W. Wong, "Effectiveness of insoles on plantar pressure redistribution," Journal of Rehabilitation Research and Development, vol. 41, no. 6A, pp. 767-774, 2004.

[23] J. C. Gilmour and Y. Burns, "The measurement of the medial longitudinal arch in children," Foot \& Ankle International, vol. 22, no. 6, pp. 493-498, 2001.

[24] P. A. Ugolini and S. M. Raikin, "The accessory navicular," Foot and Ankle Clinics the Navicular, vol. 9, no. 1, pp. 165-180, 2004.

[25] J. R. Kim, C. I. Park, Y. J. Moon, S. I. Wang, and K. S. Kwon, "Concomitant calcaneo-cuboid-cuneiform osteotomies and the modified Kidner procedure for severe flatfoot associated with symptomatic accessory navicular in children and adolescents," Journal of Orthopaedic Surgery and Research, vol. 9, no. 1, p. 131, 2014.

[26] H. Elftman, "A cinematic study of the distribution of pressure in the human foot," The Anatomical Record, vol. 59, no. 4, pp. 481-491, 1934. 


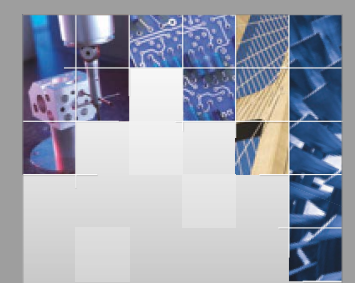

\section{Enfincering}
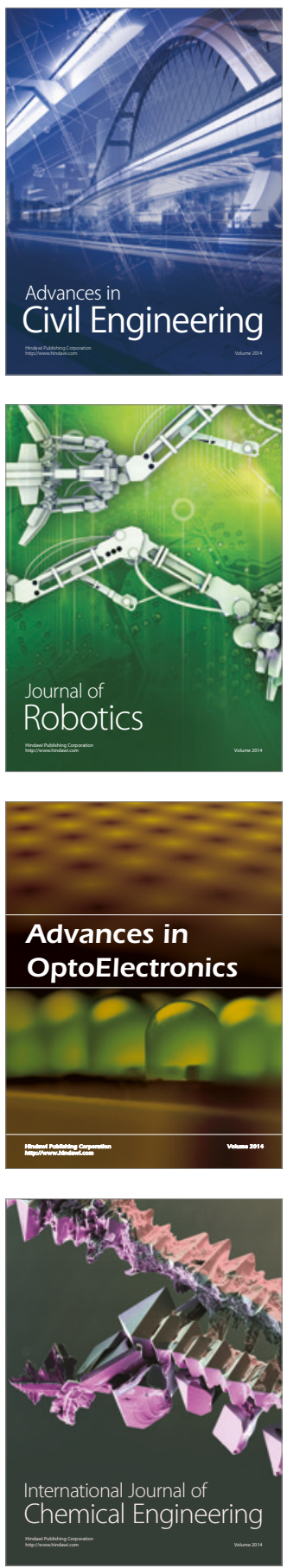

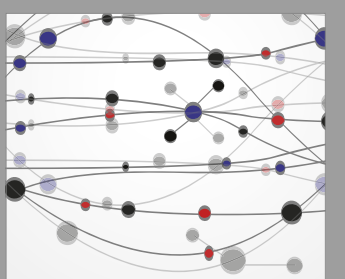

The Scientific World Journal

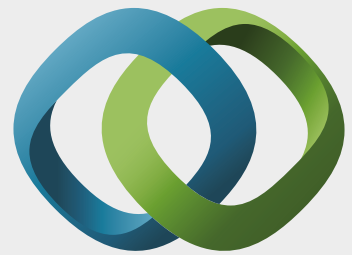

\section{Hindawi}

Submit your manuscripts at

https://www.hindawi.com
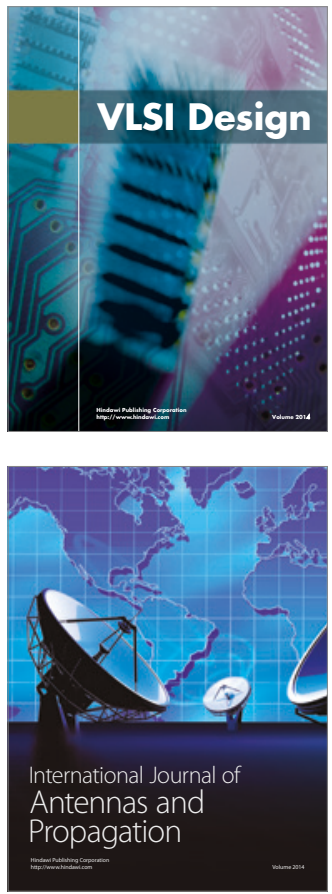

\section{Rotating}

Machinery
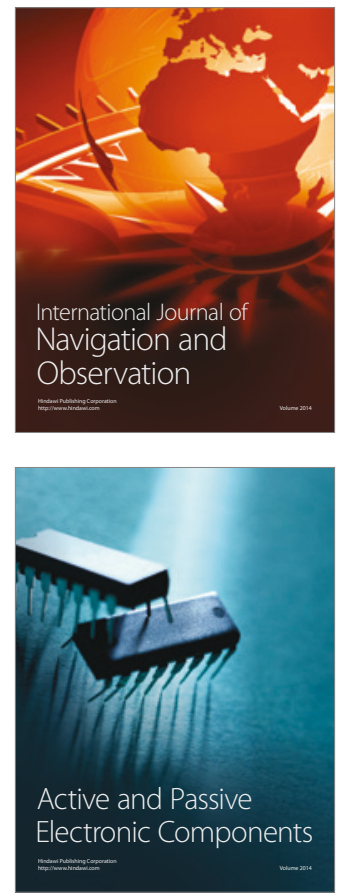
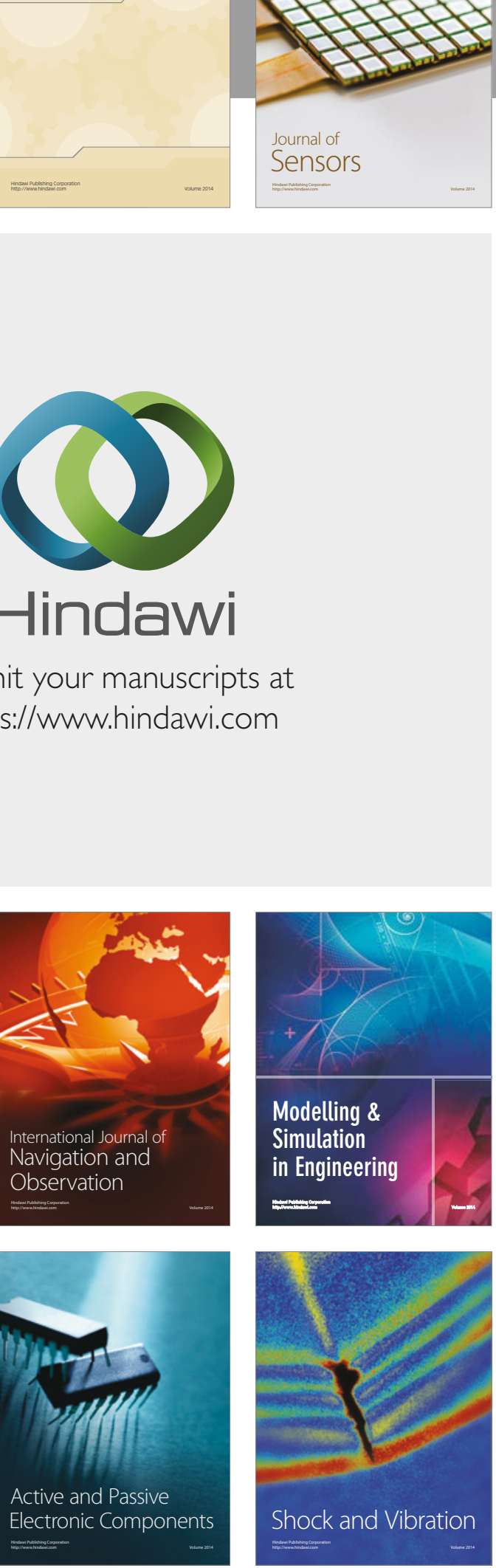
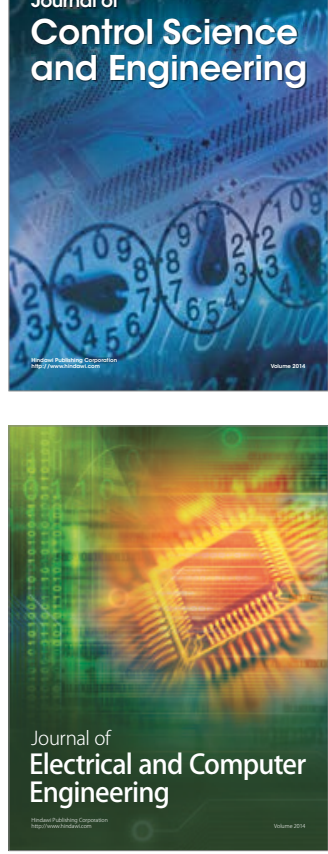

Distributed

Journal of

Control Science

and Engineering
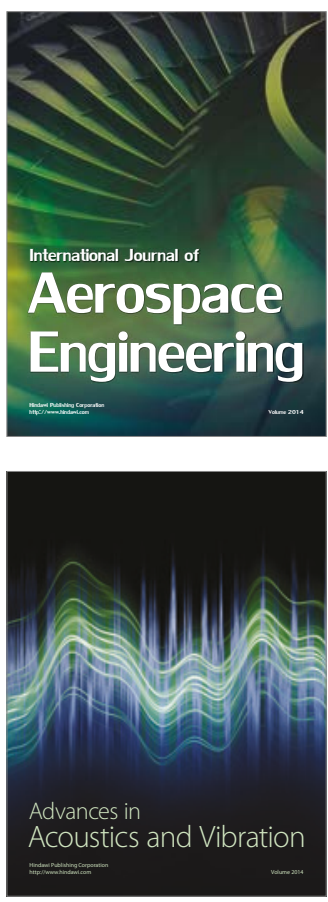

Sensor Networks 